\title{
A Research on the Quality of Public Transportation Services by Bus in Vietnam
}

\author{
Thi Hong Le Hoang, Van Lam Hoang, Thi Bich Hanh Chu \\ University of Transport Technology, Vietnam \\ Manh Dung Tran \\ National Economics University, Vietnam \\ Vu Hoang Nguyen \\ BaoViet Life, Vietnam \\ Thi Hai Anh Vu, Thi Bach Tuyet Vuong, Thi Huyen Do \\ University of Transport Technology, Vietnam
}

\begin{abstract}
This study was conducted to assess the status of the quality of public passenger transport services by bus in Hanoi. Data were collected from regular passengers using buses as a means of transportation in the city, including passengers standing at stations, waiting shelters and on vehicles to make trips and students of some universities who use buses as a means of transportation. We employ descriptive statistics and hierarchical analysis to learn about the topic of research. The results indicate that the quality of public transport services by buses in Hanoi, which was judged by passengers quite well. In particular, the safety level, convenience, security and hygiene is up to $70 \%$, which was higher than the highest quality level. Quality of fast level and reliability are low.
\end{abstract}

Keywords: quality of services, public passenger transport, buses, Vietnam.

DOI: $10.7176 /$ RJFA/10-13-04

Publication date:July $31^{\text {st }} 2019$

\section{Introduction}

Currently, most cities in Vietnam are facing the challenges of infrastructure development and management innovation which provide the public passenger transport services (PPT) with the best facilities for people, ensuring sustainable socio-economic development. In particular, PPT by bus plays an important role in providing public transport services for urban residents. The requirement of services quality have been rising higher and higher and more diverse in safety, convenience, comfort and environmental protection. However, the number of personal vehicles involved in traffic is too high while the urban transport infrastructure (UT) has not been improved, which has a significant impact on the efficiency and the quality of PPT services in many cities. Therefore, improving the quality of PPT services by bus is considered as an important solution to attract people to use public transport, enhance efficiency and develop sustainably the urban transport system.

The problem of improving the quality of PPT services by bus requires efforts and synchronous coordination of many parties, related to the policies of planning infrastructure development of urban transport, traffic operation organization and the use of services by traffic participants, especially passengers. In response to the increasing challenge of urbanization and the decline in demand for public transport in major cities in Vietnam, many solutions to improve the quality of PPT services have been studied and implemented with participation of all levels of city traffic management, transport firms, scientists and the support of citizens. However, it is necessary to study systematically the relevant factors to have a synchronous solution to enhance the efficiency and quality of PPT services in general, and PPT by bus in particular. Especially for urban areas that have not developed iron wheel transport vehicles (subway, sky train, etc.), the question of how to effectively manage and improve the quality of PPT services by buses are always an important and urgent task for city authorities and businesses involved in providing transport services.

\section{Literature Review}

From the perspective of macro management, firms, many quality management policies or more effective solutions to improve the quality of PPT services have been studied and implemented with different approaches.

Approaching the standardization of quality, the issue of service quality management in PPT in Europe is developed according to the requirements of EN 13816 (2002) and EN 15140 (2006) standards with complex quality criteria system (analysis according to three-level structure with 8 criteria and 103 targets). In particular, these standards set requirements, recommending activities which measure services quality (according to the level of passenger satisfaction) and service performance (according to the level of reaching the targets of the business). Since then, PPT firms have planned policies and implemented appropriate solutions 
In the line of researching and evaluating the performance of PPT services by bus, Aleks (2015) analyzed and evaluated the satisfaction level of passengers for the quality of transport services according to 8 criteria (road network, levels of services response, reliability, information provision, comfort, safety and security, fares and environment) with 27 indicators reflecting quality. Through a survey to assess the satisfaction of passengers, the study shows the influence of factors on service quality from which to recommend policies to improve the efficiency of PPT services in Indonesia's cities.

Also, in order to assess the impact of quality factors on service performance for passengers, Gabriella \& Laura (2006) determine the importance of quality factors through measuring the satisfaction level of the passengers; then use the method of multivariate regression analysis to determine the value of indicators that reflect the influence level of factors on the overall quality. The results of quantitative analysis of indicators provide arguments for related parties to develop appropriate solutions.

Research by Niels (2011) analyzes the quality of PPT services in Netherlands in terms of price, the ability of time and space response of transport journeys, comfort levels, and reliability of service. The research results provide a scientific basis to optimize the service system and improve the utility of PPT services in the outskirts of the city.

Developed according to the model of service quality gap (SERVQUAL, Service Quality), a number of studies have developed a system to assess the quality of PPT service with different number of targets (based on 5 components: reliability, responsiveness, assurance, empathy and tangibility) by many authors such as Benedetto (2012), Doddy (2009), Verma Meghna and colleagues (2013). These studies use the qualitative assessment of PPT service quality from passenger feedback to analyze and recommend solutions to enhance the efficiency of PPT or propose solutions to ensure sustainable transport development in urban area.

The study by Litman (2008) analyzed the value of PT services by bus provided to passengers. Through the survey of the qualitative assessment of passengers about comfort, convenience, travel time and fees combined with the analysis of transport networks and related utilities, the author recommends some management solutions to increase the value provided to passengers. Jenny (2010) used the quality criteria system according to EN 13816 standard to assess the appropriateness of utilities provided by PPT to passengers, thereby proposing necessary solutions to increase the utility which satisfies the needs and expectations of bus passengers in the Gothenburg city (Sweden).

Focusing on marketing activities of PPT firms, Bodmer and colleagues (2003) based on studies related to sustainable urban development to analyze the relationship between transport service quality and social responsibility of parties involved. This relationship raises requirements in improving service quality and complying with environmental and social safety constraints

In the line of strengthening technical solutions, some studies develop the application of ArcGIS Server technology, 3S technology (GPS, RS, GIS - satellite navigation technology, remote sensing and geographic information) to design Bus operating system (Liang et al., 2012) or building smart bus system (Shanjun et al., 2013). The establishment of a smart operating system will ensure the provision of safe, effective and maximum benefits for passengers using PPT services.

In order to innovate investment management, Borgmäster et al. (2012) studied the relationship between investment policy innovation and the improvement of PPT service quality, increased public welfare for people and brought benefits for all parties. Analysis of investment policies in PPT, Shanjun et al. (2013) recommended some solutions of innovative bidding policies, investment in vehicles to improve quality, enhance efficiency and sustainable development of PPT services by bus.

In short, under the perspective of macro management, the quality EN 13816 and EN 15140 standards have created a guiding framework for the PPT quality management activities in Europe. However, these standards only recommend what needs to be done to measure and control quality, but how to improve quality depends on the ability of each participant to provide PPT services to people. From a passenger-oriented view, most independent studies start from designing a quality feedback judge system according to the passengers, from which to analyze and recommend solutions to improve the quality of PPT services. Except for technical and technological solutions, management organization solutions only guide to implement the organization, but how the solutions implement effectively, there are few studies mentioned.

\section{Research Methodology \\ 3.1. Data Collection}

The investigation of passengers using public services is carried out in Hanoi. The samples of the research are those who regularly use buses as a means of transportation in the city, including: Passengers standing at the bus stations, the bus shelters and being on the bus to make the trip and students from several universities use buses as regular transportation. This study collects data with the use of questionnaires. To ensure the variety of samples, respondents are required to be diverse in age, occupation, accommodation and the purpose of using the bus.

With 7 criteria including 24 standards, the study used 550 questionnaires for 2 groups of passengers who are 
in the process of using buses (350 votes) and students at universities (200 votes). The number of questionnaires received was 494 votes (accounting for 90\%), there were 22 questionares that passengers were not returned (accounting for 4\%); 34 passengers doing questionnaires refused to confirm the general information and did not choose a full evaluation (accounting for $6 \%$ ).

\subsection{Research Model}

Organizing a model to evaluate the quality of public passenger transport services by bus. The quality of public passenger transport services by bus is determined by the total quality of the criteria and standards according to this equation:

$$
Q_{b u s}=\sum_{i=1}^{n} \sum_{j=1}^{k} \beta_{i, j} . A_{i, j}
$$

In which:

$Q_{b u s}:$ the quality of public passenger transport services by bus

$\beta_{\mathrm{i}, \mathrm{j}}$ : the weight of the $\mathrm{j}$ indicator in the $\mathrm{i}$ criterion

The coefficients $\beta_{\mathrm{i}, \mathrm{j}}$ satisfy the condition:

$$
\sum_{i=1}^{n} \sum_{j=1}^{k} \beta_{i, j}=1
$$

$\mathrm{A}_{\mathrm{i}, \mathrm{j}}$ : the level of the quality that assessment according to the $\mathrm{j}$ criteria in the $\mathrm{i}$ criteria; $\mathrm{n}$ : number of quality criteria;

$\mathrm{k}$ : number of quality indicators of $\mathrm{i}$ criteria.

In theory, it is possible to rely on the direct judgment of passengers to set up the Anx comparison matrix, however this method is difficult to implement because the travel time of passengers is often very short. Therefore, on the basis of analyzing the relationship between the components of the service system and the importance of factors reflecting the output quality of public passenger transport services by bus, study the pair comparison matrix among the elements of the database to determine the parameters $\beta \mathrm{i}, \mathrm{j}$ of the model.

With the system of criteria divided into 2 levels, including 07 criteria (level 1) and 24 indicators (level 2), the research applies the hierarchical analysis method (AHP) to determine the weightings $\beta \mathrm{i}, \mathrm{j}$ of the mathematical model according to formula (1) above. The process of analyzing AHP follows 3 steps.

\section{Research Results}

Step 1: Organize the comparison matrix and determine the weight for the quality criteria

Analyzing the influence and the importance of the service constituent elements, studying and proposing a pair of comparative matrices between the output quality attributes of the quality of public passenger transport services by bus including: Quickness (A1) ; Safety (A2); Reliability (A3); Convenience (A4); Comfort (A5); Security (A6); Hygiene (A7). Basically, the quickness and safety are 02 attributes that always go hand in hand that related to the quality of the infrastructure, means and organization of transport operation. These are the most important attributes among the properties reflecting the output of the quality of passenger transport services in general, and the quality of public passenger transport services by bus in particular. Reliability, convenience, comfort and security are attributes that reflect the functional quality of the service system, related to the organization of transport operators, vehicle operation and passenger service in transport process. In particular, the reliability and convenience affect the psychology and decision of the passengers to choose services, so these two elements are more important than other elements.

Table 1. Matrix of Pair Comparison among Quality Criteria

\begin{tabular}{cccccccc}
\hline & A1 & A2 & A3 & A4 & A5 & A6 & A7 \\
\hline A1 & 1 & 1 & 3 & 5 & 6 & 7 & 8 \\
A2 & 1 & 1 & 4 & 6 & 7 & 8 & 9 \\
A3 & $1 / 3$ & $1 / 4$ & 1 & 2 & 4 & 6 & 7 \\
A4 & $1 / 5$ & $1 / 6$ & $1 / 2$ & 1 & 2 & 1 & 5 \\
A5 & $1 / 6$ & $1 / 7$ & $1 / 4$ & $1 / 2$ & 1 & 1 & 3 \\
A6 & $1 / 7$ & $1 / 8$ & $1 / 6$ & 1 & 1 & 1 & 2 \\
A7 & $1 / 8$ & $1 / 9$ & $1 / 7$ & $1 / 5$ & $1 / 3$ & $1 / 2$ & 1 \\
\hline
\end{tabular}

Consistent matrix V (7.7) and weight vector are defined in tables below: 
Table 2. Matrix of Consistency of Quality Criteria

\begin{tabular}{lccccccc}
\hline & $\mathbf{A 1}$ & $\mathbf{A 2}$ & $\mathbf{A 3}$ & $\mathbf{A 4}$ & $\mathbf{A 5}$ & $\mathbf{A 6}$ & $\mathbf{A 7}$ \\
\hline $\mathbf{A 1}$ & 0.337 & 0.358 & 0.331 & 0.318 & 0.281 & 0.286 & 0.229 \\
$\mathbf{A 2}$ & 0.337 & 0.358 & 0.442 & 0.382 & 0.328 & 0.327 & 0.257 \\
$\mathbf{A 3}$ & 0.112 & 0.089 & 0.110 & 0.127 & 0.188 & 0.245 & 0.200 \\
A4 & 0.067 & 0.060 & 0.055 & 0.064 & 0.094 & 0.041 & 0.143 \\
A5 & 0.056 & 0.051 & 0.028 & 0.032 & 0.047 & 0.041 & 0.086 \\
A6 & 0.048 & 0.045 & 0.018 & 0.064 & 0.047 & 0.041 & 0.057 \\
A7 & 0.042 & 0.040 & 0.016 & 0.013 & 0.016 & 0.020 & 0.029 \\
\hline
\end{tabular}

The next table presents the weight vectors of quality criteria, below:

Table 3. Weight vectors of quality criteria

\begin{tabular}{l|lllllll} 
Weights & $\beta_{\mathrm{A} 1}$ & $\beta_{\mathrm{A} 2}$ & $\beta_{\mathrm{A} 3}$ & $\beta_{\mathrm{A} 4}$ & $\beta_{\mathrm{A} 5}$ & $\beta_{\mathrm{A} 6}$ & $\beta_{\mathrm{A} 7}$ \\
\hline Value & $\mathbf{0 . 3 0 6}$ & $\mathbf{0 . 3 4 7}$ & $\mathbf{0 . 1 5 2}$ & $\mathbf{0 . 0 7 5}$ & $\mathbf{0 . 0 4 9}$ & $\mathbf{0 . 0 4 6}$ & $\mathbf{0 . 0 2 5}$
\end{tabular}

$(\lambda=7.3167 ; \mathrm{CI}=0.05<0.1 ; \mathrm{RI}=1.32 ; \mathrm{CR}(\mathrm{CI} / \mathrm{RI})=0.04<0.1)$

Step 2: Prepare the comparison matrix and determine the weight for the indicator in each criterion

- Rapidity criteria (A1)

Of the indicators reflecting the degree of Rapidity, the level of satisfaction of passengers on the time of bus travel (from the bus station the passenger get on the bus to the one they get off the bus) is more important than the satisfaction about the time of walking and waiting. In fact, the bus run time is critical to the total transportation time of the passenger. After that, the waiting time of passengers at the bus stop will be more meaningful than the time that passengers have to walk from their departure to the bus station, because the larger the waiting time, the more tired the passenger will feel (Table 4).

The analytical results determine a consistent matrix, the weights of indicators reflecting the rapidity are shown in Table 5, the weight of indicator A1.3 has the largest value (0.623).

Table 4. Pairwise Comparison Matrix of Rapidity Indicators

\begin{tabular}{|c|c|c|c|}
\hline & A1.1 & A1.2 & A1.3 \\
\hline $\mathbf{A 1 . 1}$ & 1 & $1 / 2$ & $1 / 4$ \\
\hline $\mathbf{A 1 . 2}$ & 2 & 1 & $1 / 3$ \\
\hline $\mathbf{A 1 . 3}$ & 4 & 3 & 1 \\
\hline
\end{tabular}

Table 5. Consistency Matrix and Weight Vector of Indicators Reflecting Rapidity

\begin{tabular}{ccccc}
\hline & A1.1 & A1.2 & A1.3 & Weights \\
\hline A1.1 & 0.143 & 0.111 & 0.158 & $\boldsymbol{\beta}_{\text {A1.1 }}=\mathbf{0 . 1 3 7}$ \\
A1.2 & 0.286 & 0.222 & 0.211 & $\boldsymbol{\beta}_{\text {A1.2 }}=\mathbf{0 . 2 3 9}$ \\
A1.3 & 0.571 & 0.667 & 0.632 & $\boldsymbol{\beta}_{\text {A1.3 }}=\mathbf{0 . 6 2 3}$ \\
\hline
\end{tabular}

$(\lambda=3.0183 ; \mathrm{CI}=0.01<0.1 ; \mathrm{RI}=0.58 ; \mathrm{CR}(\mathrm{CI} / \mathrm{RI})=0.02<0.1)$

- Safety criteria (A2)

Safety criteria include 02 indicators A2.1. Safety level for passengers and A2.2. Traffic safety level. Basically, both traffic safety and passenger safety are mandatory requirements for all means of transport. From the perspective of passengers using public bus passenger transport service, safety issues for passengers are the first priority. However, the operation of the bus on the road must also ensure general traffic safety for other vehicles to join. Therefore, safety for bus passengers and traffic safety can be evaluated as the same importance. It means that the weights of safety indicator for passengers (A.2.1) and traffic safety (A2.2) are equal to 0.5. The weights: $\beta_{\mathrm{A} 2.1}$ $=\beta_{\mathrm{A} 2.2}=0.5$

- Reliability criteria (A3)

Reliability criteria (A3) consists of 03 indicators A3.1: The level of punctuality when leaving the first port; A3.2. The level of punctuality when arriving at the terminal; A3.3. Level of punctuality when passing stops along the route.

The level of punctuality when leaving the first port affects the punctuality of the entire route. From a passenger perspective, the level of punctuality when the vehicle passes through stops along the road affects the waiting time of passengers. In particular, the waiting time of passengers will be prolonged when the time of arrival at the stops is unstable, which may be earlier or later. In that sense, the indicator of punctuality when passing through stops along the road is evaluated as higher importance. 
Table 6. Pairwise Comparison Matrix of Reliability Indicators

\begin{tabular}{cccc}
\hline & A3.1 & A3.2 & A3.3 \\
\hline A3.1 & 1 & 4 & $1 / 2$ \\
A3.2 & $1 / 4$ & 1 & $1 / 3$ \\
A3.3 & 2 & 3 & 1 \\
\hline
\end{tabular}

Table 7. Consistency matrix and weight vector of indicators reflecting the reliability

\begin{tabular}{ccccc}
\hline & A3.1 & A3.2 & A3.3 & Weights \\
\hline A3.1 & 0.308 & 0.500 & 0.273 & $\boldsymbol{\beta}_{\text {A3.1 }}=\mathbf{0 . 3 6 0}$ \\
A3.2 & 0.077 & 0.125 & 0.182 & $\boldsymbol{\beta}_{\text {A3.2 }}=\mathbf{0 . 1 2 8}$ \\
A3.3 & 0.615 & 0.375 & 0.545 & $\boldsymbol{\beta}_{\text {A3.3 }}=\mathbf{0 . 5 1 2}$ \\
\hline
\end{tabular}

$(\lambda=3.1086 ; \mathrm{CI}=0.05<0.1 ; \mathrm{RI}=0.58 ; \mathrm{CR}(\mathrm{CI} / \mathrm{RI})=0.09<0.1)$

\section{- Convenience criteria (A4)}

The ease level of access to network information, bus route schedules and ticket purchase are the top concerns for passengers. The level of convenience when getting on/off will ensure safety and satisfy passengers on the ride. After that, the passengers must transfer from one bus to another bus, from the bus to other means of transport will be interested in 02 indicators A4.4 and A4.5.

Table 8. Pairwise comparison matrix of convinience indicators

\begin{tabular}{cccccc}
\hline & $\mathbf{A 4 . 1}$ & $\mathbf{A 4 . 2}$ & $\mathbf{A 4 . 3}$ & $\mathbf{A 4 . 4}$ & $\mathbf{A 4 . 5}$ \\
\hline $\mathbf{A 4 . 1}$ & 1 & $1 / 3$ & $1 / 2$ & 3 & 4 \\
$\mathbf{A 4 . 2}$ & 3 & 1 & 2 & 4 & 6 \\
$\mathbf{A 4 . 3}$ & 2 & $1 / 2$ & 1 & 3 & 5 \\
$\mathbf{A 4 . 4}$ & $1 / 3$ & $1 / 4$ & $1 / 3$ & 1 & 2 \\
$\mathbf{A 4 . 5}$ & $1 / 4$ & $1 / 6$ & $1 / 5$ & $1 / 2$ & 1 \\
\hline
\end{tabular}

Table 9. Consistency matrix of pairwise comparison and weight vectors of convenience indicators

\begin{tabular}{llllllc}
\hline & $\mathbf{A 4 . 1}$ & $\mathbf{A 4 . 2}$ & $\mathbf{A 4 . 3}$ & $\mathbf{A 4 . 4}$ & $\mathbf{A 4 . 5}$ & Weights \\
\hline $\mathbf{A 4 . 1}$ & 0.152 & 0.148 & 0.124 & 0.261 & 0.222 & $\boldsymbol{\beta}_{\text {A4.1 }}=\mathbf{0 . 1 8 1}$ \\
$\mathbf{A 4 . 2}$ & 0.456 & 0.444 & 0.496 & 0.348 & 0.333 & $\boldsymbol{\beta}_{\text {A4.2 }}=\mathbf{0 . 4 1 5}$ \\
$\mathbf{A 4 . 3}$ & 0.304 & 0.222 & 0.248 & 0.261 & 0.278 & $\boldsymbol{\beta}_{\text {A4.3 }}=\mathbf{0 . 2 6 3}$ \\
$\mathbf{A 4 . 4}$ & 0.051 & 0.111 & 0.083 & 0.087 & 0.111 & $\boldsymbol{\beta}_{\text {A4.4 }}=\mathbf{0 . 0 8 8}$ \\
$\mathbf{A 4 . 5}$ & 0.038 & 0.074 & 0.050 & 0.043 & 0.056 & $\boldsymbol{\beta}_{\text {A4.5 }}=\mathbf{0 . 0 5 2}$ \\
\hline
\end{tabular}

$(\lambda=5.107 ; \mathrm{CI}=0.03<0.1 ; \mathrm{RI}=1.12 ; \mathrm{CR}(\mathrm{CI} / \mathrm{RI})=0.02<0.1)$

\section{- Comfort criteria(A5)}

The level of satisfaction with the attitude of employees, the temperature and air conditions, the noise on the bus, the smoothness when the bus runs on the road and the space used on the car is the factors that make up the comfort for passengers. In addition, the response to passengers who are priority subjects such as people with disabilities, the elderly, pregnant women and children express the humanity of public transport services in general and bus transportation in particular. From a passenger perspective, the attitude of employees, conditions of temperature and air, noise; the smoothness of the bus when running are the factors that are of top concern, then the level of response to priority subjects; finally is the space used on the bus.

Table 10. Pairwise comparison matrix of Comfort indicators

\begin{tabular}{cccccc}
\hline & $\mathbf{A 5 . 1}$ & $\mathbf{A 5 . 2}$ & $\mathbf{A 5 . 3}$ & $\mathbf{A 5 . 4}$ & $\mathbf{A 5 . 5}$ \\
\hline $\mathbf{A 5 . 1}$ & 1 & 2 & 1 & $1 / 5$ & $1 / 2$ \\
$\mathbf{A 5 . 2}$ & $1 / 2$ & 1 & $1 / 2$ & $1 / 3$ & $1 / 2$ \\
$\mathbf{A 5 . 3}$ & 1 & 2 & 1 & $1 / 2$ & 2 \\
$\mathbf{A 5 . 4}$ & 5 & 3 & 2 & 1 & 3 \\
$\mathbf{A 5 . 5}$ & 2 & 2 & $1 / 2$ & $1 / 3$ & 1 \\
\hline
\end{tabular}

Table 11. Consistency matrix of pairwise comparison and weight vectors of convenience indicators

\begin{tabular}{ccccccc}
\hline & A5.1 & $\mathbf{A 5 . 2}$ & $\mathbf{A 5 . 3}$ & $\mathbf{A 5 . 4}$ & $\mathbf{A 5 . 5}$ & Weights \\
\hline $\mathbf{A 5 . 1}$ & 0.105 & 0.200 & 0.200 & 0.085 & 0.071 & $\boldsymbol{\beta}_{\text {A5.1 }}=\mathbf{0 . 1 3 2}$ \\
$\mathbf{A 5 . 2}$ & 0.053 & 0.100 & 0.100 & 0.141 & 0.071 & $\boldsymbol{\beta}_{\text {A5.2 }}=\mathbf{0 . 0 9 3}$ \\
$\mathbf{A 5 . 3}$ & 0.105 & 0.200 & 0.200 & 0.211 & 0.286 & $\boldsymbol{\beta}_{\text {A5.3 }}=\mathbf{0 . 2 0 0}$ \\
$\mathbf{A 5 . 4}$ & 0.526 & 0.300 & 0.400 & 0.423 & 0.429 & $\boldsymbol{\beta}_{\text {A5.4 }}=\mathbf{0 . 4 1 5}$ \\
$\mathbf{A 5 . 5}$ & 0.211 & 0.200 & 0.100 & 0.141 & 0.143 & $\boldsymbol{\beta}_{\text {A5.5 }}=\mathbf{0 . 1 5 9}$ \\
\hline
\end{tabular}

$(\lambda=5.241 ; \mathrm{CI}=0.06<0.1 ; \mathrm{RI}=1.12 ; \mathrm{CR}(\mathrm{CI} / \mathrm{RI})=0.05<0.1)$ 


\section{- Security criteria (A6)}

From a passenger perspective, the level of security on the bus is the most important factor, since this is the time when passengers can be unsafe of property (due to theft), harassment or other social evils; then the safety of passengers at stops (due to the lack of security forces as at the bus station).

Pairwise comparison matrix, consistency matrix and weight vectors of security quality evaluation criteria are shown in Tables below. In particular, the level of security and safety for passengers in the bus are the most important indicators with weight $\beta_{\mathrm{A} 6.3}=0.557$; then security issues for passengers at the bus stops $\beta_{\mathrm{A} 6.2}=0.320$.

Table 12. Pairwise comparison matrix of security indicators

\begin{tabular}{cccc}
\hline & A6.1 & A6.2 & A6.3 \\
\hline A6.1 & 1 & $1 / 3$ & $1 / 4$ \\
A6.2 & 3 & 1 & $1 / 2$ \\
A6.3 & 4 & 2 & 1 \\
\hline
\end{tabular}

Table 13. Consistency matrix and weight vectors of indicators reflecting Security level

\begin{tabular}{ccccc}
\hline & A6.1 & A6.2 & A6.3 & Weights \\
\hline A6.1 & 0.125 & 0.100 & 0.143 & $\boldsymbol{\beta}_{\text {A6.1 }}=\mathbf{0 . 1 2 3}$ \\
A6.2 & 0.375 & 0.300 & 0.286 & $\boldsymbol{\beta}_{\text {A6.2 }}=\mathbf{0 . 3 2 0}$ \\
$\mathbf{A 6 . 3}$ & 0.500 & 0.600 & 0.571 & $\boldsymbol{\beta}_{\text {A6.3 }}=\mathbf{0 . 5 5 7}$ \\
\hline
\end{tabular}

\section{- Hygiene criteria (A7)}

$(\lambda=3.0183 ; \mathrm{CI}=0.01<0.1 ; \mathrm{RI}=0.58 ; \mathrm{CR}(\mathrm{CI} / \mathrm{RI})=0.02<0.1)$

Hygienic condition on the bus is the most important factor compared to stops and bus stations because the level of cleanliness in the bus has a strong impact on the passenger's perception of service quality. Passengers often pay less attention to hygiene at roadside stops because the time they wait at the stop is very short. But at transfer stations and bus stations, passengers will pay more attention to hygiene. Pairwise comparison matrix, consistency matrix and weight vectors of quality evaluation indicators:

Table 14. Pairwise comparison matrix of Hygiene indicators

\begin{tabular}{cccc} 
& $\mathbf{A 7 . 1}$ & $\mathbf{A 7 . 2}$ & $\mathbf{A 7 . 3}$ \\
\hline $\mathbf{A} 7.1$ & 1 & 2 & $1 / 4$ \\
$\mathbf{A} 7.2$ & $1 / 2$ & 1 & $1 / 3$ \\
$\mathbf{A} 7.3$ & 4 & 3 & 1 \\
\hline
\end{tabular}

Table 15. Consistency matrix and weight vectors of indicators reflecting Hygiene level

\begin{tabular}{lllll}
\hline & A7.1 & A7.2 & A7.3 & Weights \\
\hline A7.1 & 0.182 & 0.333 & 0.158 & $\boldsymbol{\beta}_{\text {A7.1 }}=\mathbf{0 . 2 2 4}$ \\
A7.2 & 0.091 & 0.167 & 0.211 & $\boldsymbol{\beta}_{\text {A7.1 }}=\mathbf{0 . 1 5 6}$ \\
A7.3 & 0.727 & 0.500 & 0.632 & $\boldsymbol{\beta}_{\text {A7.1 }}=\mathbf{0 . 6 2 0}$ \\
\hline
\end{tabular}

$(\lambda=3.1092 ; \mathrm{CI}=0.05<0.1 ; \mathrm{RI}=0.58 ; \mathrm{CR}(\mathrm{CI} / \mathrm{RI})=0.09<0.1)$

Step 3: Overall weight of the indicators reflecting the quality of public bus passenger transport service The overall weight of each indicator reflects the quality attribute determined by the product of the weight of the quality criteria and the weight of each indicator in the same group of quality criteria.

In which:

$$
\beta_{\mathrm{i}, \mathrm{j}}=\beta_{\mathrm{Ai} \cdot} \beta_{\text {Ai.j }}
$$

$\beta_{\mathrm{i}, \mathrm{j}}$ : weight of the $\mathrm{j}$ indicator in criterion $\mathrm{i}$;

$\beta_{\mathrm{Ai}}$ : weight of $\mathrm{Ai}$ indicator in 7 comparison criteria;

$\beta_{\mathrm{Ai}, \mathrm{j}}$ : component weight of the $\mathrm{j}$ indicator in Ai criteria group; 
Table 16. Weights showing the importance of quality criteria and criteria

\begin{tabular}{|c|c|c|c|c|c|}
\hline No. & Criteria & $\beta_{\mathrm{Ai}}$ & Indicators & $\beta_{A i . j}$ & $\beta_{i . j}$ \\
\hline \multirow{3}{*}{1} & \multirow{3}{*}{ A1. Rapidity } & \multirow{3}{*}{0.306} & A1.1 & 0.137 & 0.042 \\
\hline & & & A 1.2 & 0.239 & 0.073 \\
\hline & & & A 1.3 & 0.623 & 0.191 \\
\hline \multirow{2}{*}{2} & \multirow{2}{*}{ A2. Safety } & \multirow{2}{*}{0.347} & A2.1 & 0.500 & 0.174 \\
\hline & & & $\mathrm{A} 2.2$ & 0.500 & 0.174 \\
\hline \multirow{3}{*}{3} & \multirow{3}{*}{ A3. Reliability } & \multirow{3}{*}{0.152} & A3.1 & 0.360 & 0.055 \\
\hline & & & A3. 2 & 0.128 & 0.019 \\
\hline & & & A3.3 & 0.512 & 0.078 \\
\hline \multirow{5}{*}{4} & \multirow{5}{*}{ A4. Convenience } & \multirow{5}{*}{0.075} & A4.1 & 0.181 & 0.014 \\
\hline & & & A 4.2 & 0.415 & 0.031 \\
\hline & & & A4. 3 & 0.263 & 0.020 \\
\hline & & & A4.4 & 0.088 & 0.007 \\
\hline & & & A4.5 & 0.052 & 0.004 \\
\hline \multirow{5}{*}{5} & \multirow{5}{*}{ A5. Comfort } & \multirow{5}{*}{0.049} & A5.1 & 0.132 & 0.006 \\
\hline & & & A5.2 & 0.093 & 0.005 \\
\hline & & & A5.3 & 0.200 & 0.010 \\
\hline & & & A5.4 & 0.415 & 0.020 \\
\hline & & & A5.5 & 0.159 & 0.008 \\
\hline \multirow{3}{*}{6} & \multirow{3}{*}{ A6. Security } & \multirow{3}{*}{0.046} & A6.1 & 0.123 & 0.006 \\
\hline & & & A6.2 & 0.320 & 0.015 \\
\hline & & & A6.3 & 0.557 & 0.026 \\
\hline \multirow{4}{*}{7} & \multirow{3}{*}{ A7. Hygiene } & \multirow{3}{*}{0.025} & A7.1 & 0.224 & 0.006 \\
\hline & & & A7.2 & 0.156 & 0.004 \\
\hline & & & A7.3 & 0.620 & 0.016 \\
\hline & Total & 1.000 & & & 1.000 \\
\hline
\end{tabular}

The quality of public bus passenger transport service is assessed by a passenger according to the mathematical model in formula 1 with the weight $\beta_{i, j}$ in Table $16, A_{i}$, is the quality assessment point according to the perception of passengers ( from 0 to 5 points). Based on the evaluation of each passenger, the service quality of public passenger transport is determined by the average value of $\mathrm{N}$ passengers asked for feedback.

$$
\bar{Q}_{x e-b u \text { 踚 }}=\frac{1}{N} \sum_{i=1}^{N} Q_{x e-b u y t(i)}
$$

In which: $\bar{Q}_{x e-b u \text { 齙: }}$ The average overall quality of public bus passenger transport service; $\mathrm{Q}$ xe-buyt (i): The quality level of public bus passenger transport service according to the rating of the $\mathrm{i}$ passenger (according to formula 1 with the weights $\beta_{\mathrm{i}, \mathrm{j}}$ in Table 16).

\section{Discussions}

When evaluating on a scale of 5 for each indicator reflecting the quality attributes of the service, most passengers rated at average ( 2 points) and above average (from 2 to 5 points). In which, indicators reflecting safety level (A2), convenience (A4) and security (A6) are highly appreciated by passengers; the number of passengers for points 4 and 5 accounted for a high proportion ( $47 \%$ gave a point of $4.36 \%$ gave a score of 5 ). The rapidity and reliability are rated with lower quality, the highest value is 4 points (accounting for 26\%), the lowest point is 1 (accounting for $17 \%$ ). This explains the fact that frequent traffic congestion leads to a reduction in vehicle operation rapidity and is difficult to ensure compliance with the driver's driving diagrams.

Applying evaluation model with weight $\beta_{\mathrm{i}, \mathrm{j}}$ (Table 16), service quality of public bus passenger tránport is summarized in Table 17. 
Table 17. Quality of public bus passenger transport service in Hanoi city (according to the proposed model)

\begin{tabular}{|c|c|c|c|c|c|c|c|c|c|c|}
\hline \multirow{3}{*}{$\mathbf{A}$} & \multirow{3}{*}{ Indicators } & \multirow{2}{*}{\multicolumn{3}{|c|}{$\begin{array}{l}\text { Quality according to the } \\
\text { passenger's evaluation }\end{array}$}} & \multicolumn{6}{|c|}{ Quality according to model's evaluation } \\
\hline & & & & & \multicolumn{3}{|c|}{ Evaluation by criteria } & \multicolumn{3}{|c|}{ Evaluation by indicators } \\
\hline & & Highest & Lowest & Average & Highest & Lowest & Average & Highest & Lowest & Average \\
\hline \multirow{3}{*}{ A1 } & $\mathrm{A} 1.1$ & 4 & 1 & 2.716 & 0.168 & 0.042 & 0.114 & & & \\
\hline & A 1.2 & 4 & 1 & 2.193 & 0.292 & 0.073 & 0.160 & 1.151 & 0.463 & 0.857 \\
\hline & A1.3 & 4 & 1 & 3.054 & 0.764 & 0.191 & 0.583 & & & \\
\hline \multirow{3}{*}{ A2 } & A 2.1 & 5 & 3 & 4.216 & 0.870 & 0.522 & 0.734 & & & \\
\hline & $\mathrm{A} 2.2$ & 5 & 3 & 3.997 & 0.870 & 0.522 & 0.696 & 1.740 & 1.044 & 1.429 \\
\hline & A 3.1 & 4 & 2 & 3.003 & 0.220 & 0.110 & 0.165 & & & \\
\hline \multirow[t]{4}{*}{ A3 } & A3. 2 & 4 & 1 & 2.009 & 0.080 & 0.020 & 0.040 & 0.592 & 0.283 & 0.416 \\
\hline & A 3.3 & 4 & 1 & 2.699 & 0.312 & 0.078 & 0.211 & & & \\
\hline & A4.1 & 5 & 2 & 3.327 & 0.070 & 0.028 & 0.047 & & & \\
\hline & A4 4.2 & 5 & 3 & 3.903 & 0.155 & 0.093 & 0.121 & & & \\
\hline \multirow[t]{5}{*}{ A4 } & A 4.3 & 5 & 2 & 3.477 & 0.100 & 0.040 & 0.070 & 0.345 & 0.191 & 0.272 \\
\hline & A4.4 & 5 & 2 & 3.213 & 0.035 & 0.014 & 0.022 & & & \\
\hline & A 4.5 & 4 & 2 & 3.023 & 0.016 & 0.008 & 0.012 & & & \\
\hline & A5.1 & 4 & 2 & 3.014 & 0.016 & 0.008 & 0.012 & & & \\
\hline & A5.2 & 4 & 3 & 3.315 & 0.024 & 0.018 & 0.020 & & & \\
\hline \multirow[t]{4}{*}{ A5 } & A5.3 & 5 & 3 & 3.514 & 0.025 & 0.015 & 0.018 & 0.210 & 0.131 & 0.167 \\
\hline & A5.4 & 5 & 3 & 3.739 & 0.050 & 0.030 & 0.037 & & & \\
\hline & A5.5 & 5 & 3 & 4.009 & 0.100 & 0.060 & 0.080 & & & \\
\hline & A6.1 & 5 & 3 & 4.017 & 0.030 & 0.018 & 0.024 & & & \\
\hline \multirow[t]{3}{*}{ A6 } & A6. 2 & 5 & 3 & 4.108 & 0.075 & 0.045 & 0.062 & 0.235 & 0.141 & 0.197 \\
\hline & A6.3 & 5 & 3 & 4.287 & 0.130 & 0.078 & 0.111 & & & \\
\hline & A7.1 & 4 & 3 & 3.281 & 0.024 & 0.018 & 0.020 & & & \\
\hline \multirow[t]{3}{*}{ A7 } & A7.2 & 4 & 3 & 3.307 & 0.016 & 0.012 & 0.013 & 0.120 & 0.078 & 0.096 \\
\hline & A7.3 & 5 & 3 & 3.960 & 0.080 & 0.048 & 0.063 & & & \\
\hline & \multicolumn{7}{|c|}{ Quality of public bus passenger transport service } & 4.393 & 2.331 & 3.434 \\
\hline
\end{tabular}

According to Table 16, service quality is evaluated at a fairly good level, reaching $3.434 / 5$ points (approximately $67 \%$ of the maximum quality). In particular, the quality point for safety reaches the highest level of 1.429 , accounting for $41 \%$; quality point for rapidity reaches 0.857 , accounting for approximately $25 \%$; quality point for hygiene accounts for the lowest proportion of $2 \%$.

If there is comparison between the level of quality achieved and the expected quality (calculated according to the weight and maximum quality point ( 5 points)), the quality criteria are all over $50 \%$ of the requirement but not yet reached the maximum point. In particular, safety, security, hygiene and convenience criteria reach over $70 \%$ compared to the maximum quality requirements. The reliability and rapidity reach the lowest level, less than $60 \%$ of the maximum quality requirements.

Table 18. The level of meeting the maximum quality requirements of each quality criterion

\begin{tabular}{cccccc}
\hline Item & Quality criteria & Weight & $\begin{array}{c}\text { Max quality } \\
\text { level (points) }\end{array}$ & $\begin{array}{c}\text { Real quality } \\
\text { (points) }\end{array}$ & $\begin{array}{c}\text { The level of } \\
\text { response (\%) }\end{array}$ \\
\hline A1 & Rapidity & 0.306 & 1.530 & 0.857 & 56.01 \\
A2 & Safety & 0.347 & 1.735 & 1.429 & 82.36 \\
A3 & Reliability & 0.152 & 0.760 & 0.416 & 54.74 \\
A4 & Convienience & 0.075 & 0.375 & 0.272 & 72.53 \\
A5 & Cpmfort & 0.049 & 0.245 & 0.167 & 68.16 \\
A6 & Security & 0.046 & 0.230 & 0.197 & 85.65 \\
A7 & Hygiene & 0.025 & 0.125 & 0.096 & 76.80 \\
\hline \multicolumn{7}{r}{} \\
\hline
\end{tabular}

According to the quality evaluation results from passenger feedback, the study applies the mathematical model according to formula 1 with the weights $\mathrm{i}, \mathrm{j}$ (Table 16) to measure the quality and analyze the level of attainment for each output quality of the service. Basically, the quality of public bus passenger transport service in Hanoi city is evaluated at a good level (3.343 points/5 points). In particular, safety, security and hygiene issues are highly appreciated by passengers. This is in line with the current reality, in which the innovation of vehicles, the innovation of management and administration and service organization management have ensured quite good safety and security issues for passengers. The level of convenience is also highly appreciated by passengers due to the significant improvement in information provision (by internet network), organization of ticket purchase and the ability to connect between local bus routes in the city. However, the quality of rapidity and reliability is not 
appreciated by passengers, with a level of response below $60 \%$ of the maximum level (expected quality).

In short, in general, the quality of public bus passenger transport service in Hanoi city is rated quite well by passengers. In particular, the level of responsiveness to safety, convenience, security and hygiene is $70 \%$ higher than the highest quality level. The rapidity and reliability are still low. Analysis of the rapidity evaluation results shows that the satisfaction level of passengers on walking time, the waiting time at the stops was lower than the satisfaction level of passengers on the bus during transportation. Although the walking time depends on the location of the departure and destination for each passenger, the evaluation results partly explain the reasonable level of the route and bus stop network arrangement. The waiting time of passengers has not met the expectations of passengers.

In short, improving the quality of public passenger transport service in general, public bus passenger transport in particular of each city is a regular task, requiring close coordination and efforts of city authorities, transport firms and other related parties. The important goal of improving the quality of public passenger transport service is to satisfy the maximum travel demand by effective solutions to bring the best benefits to the people. Setting in the public bus passenger transport system in Hanoi city, we investigage determinants infuencing the quality of public bus passenger transport service that meet the travel needs with the best facilities for people. The results indicate that the quality of public bus transport services in Hanoi capital of Vietnam is evaluated by passengers quite well. In particular, the level of responsiveness to safety, convenience, security and hygiene is $70 \%$ higher than the highest quality level. Rapidity and reliability quality are still low.

\section{References}

Aleks, A. P. (2015), A study on evaluating Urban Bus Service Performance in developing countries: Case Studies of Medium-sized Cities in Indonesia, $\mathrm{PhD}$ Thesis, Yokohama University.

Benedetto, B., Eusebio, D., Proto, T. (2012), Measuring service quality in urban bus transport: a modified SERVQUAL approach, International Journal of Quality and Service Sciences, 4(3), 238 - 252.

Bodmer, M., Martins, J. A. (2003), Transport Service Quality and Social Responsibility through the relationship marketing, Lectures at Federal University of Rio de Janeiro.

Borgmäster, T., and Mohlin, D. (2012), A Qualitative Journey: How to develop the quality of Swedish public bus transport by public-private cooperation, UPPSALA UNIVERSITY, Department of Business Studies, Spring Semester.

Doddy, H. W. (2009), Study of Service quality in the Public Bus Transport: Customer Complaint handling and Service Standards Design, Karlstads Universitets.

Gabriella, M. \& Laura, E. (2006), A Service Quality experimental measure for public transport, European Transport, 34, 42-53.

Jenny, K. (2010), Passengers' Valuation of Quality in Public Transport with Focus on Comfort, Department of Civil and Environmental Engineering, Division of Geoengineering Road and Traffic Group. Chalmers University of Technology, Sweden.

Liang, X., Shasha, G., Haitao, Z. (2012), Dynamic bus monitoring and scheduling system based on ArcGIS Server technology, Computer Science and Information Processing (CSIP), International Conference, 1438 - 1441.

Niels, V. O. (2011), Service Reliability and Urban Public Transport Design, PhD Thesis, the Netherlands TRAIL Research School.

Shanjun, L., Matthew, E. K., Jerry, N. (2013), The Political Economy of Public Bus Procurement: The Role of Regulation, Energy Prices and Federal Subsidies, Journal of Urban Economics, 87, 57-71.

Todd, L. (2008), Valuing Transit Service Quality Improvements, Victoria Transport Policy Institute, Journal of Public Transportation, 11(2), 22-29.

Verma, M., Verma, A., Ajith, P., \& Sindhe, S. (2013), Urban bus transport service quality and sustainable development: understanding the gaps, $13^{\text {th }}$ World Conference on Transport Research.

Vladimír, K., Maria, K. (2014), The possibilities of standardizing the Quality level in Public Passenger Transport from Customer point of view, Electronic Technical Journal of Technology, engineering and logistics in transport, 2, 26-37. 